\title{
Enhanced anti-inflammatory effect of resveratrol and EPA in treated endotoxin-activated RAW 264.7 macrophages
}

\author{
Victor Pallarès ${ }^{1}$, Damien Calay ${ }^{2}$, Lídia Cedó ${ }^{1}$, Anna Castell-Auví ${ }^{1}$, Martine Raes ${ }^{2}$, Montserrat Pinent ${ }^{1}$, \\ Anna Ardévol ${ }^{1}$, Lluís Arola ${ }^{1}$ and Mayte Blay $^{1 *}$ \\ ${ }^{1}$ Departament de Bioquímica i Biotecnologia, Universitat Rovira i Virgili, Marcellí Domingo, $s / n$ 43007, Tarragona, Spain \\ ${ }^{2}$ Department of Biochemistry and Cellular Biology, University of Namur (FUNDP-URBC), Namur, Belgium
}

(Submitted 7 June 2011 - Final revision received 23 November 2011 - Accepted 23 November 2011 - First published online 6 January 2012)

\begin{abstract}
Macrophages play an important role in immunogenic challenges by producing reactive oxygen species, NO and proinflammatory cytokines that can aggravate and propagate local inflammation. Multiple mechanisms regulate these inflammatory processes. NF- $\mathrm{B}$ and activator protein 1 pathways are crucial in the expression of proinflammatory genes, such as TNF- $\alpha$, IL- 1 ( $\alpha$ or $\beta$ ) and -6 . Some polyphenols, which are present in beverages, vegetables and fruits, and PUFA, which are present in marine oils and fish food, possess anti-inflammatory effects in vivo and in vitro. Our aim in the present study was to assess whether polyphenols and PUFA have synergistic anti-inflammatory effects in murine macrophages in vitro. Inflammation in RAW 264.7 macrophages was induced by lipopolysaccharide at $100 \mathrm{ng} / \mathrm{ml}$. The treatments with molecules were performed by co-incubation for $19 \mathrm{~h}$. A NO production assay by Griess reaction, a phosphoprotein assay by Pathscan ELISA kit and gene expression analysis using the TaqMan ${ }^{\circledR}$ Low-density Array for ninety-one genes related to inflammation, oxidative stress and metabolism were performed to assess the synergistic anti-inflammatory effects of polyphenols, epigallocatechin gallate and resveratrol (Res; $2.5 \mu \mathrm{g} / \mathrm{ml}$ ), and the PUFA, DHA and EPA (30 $\mu \mathrm{m})$. Adding Res + EPA had an enhanced anti-inflammatory effect, in comparison with EPA and Res alone, leading to decreased NO levels; modulating the phospho-stress activated protein kinase/Jun N-terminal kinase (P-SAPK/JNK) level; down-regulating proinflammatory genes, such as IL, chemokines, transcription factors; and up-regulating several antioxidant genes. Therefore, this combination has a stronger anti-inflammatory effect than either of these molecules separately in RAW macrophages.
\end{abstract}

Key words: Macrophages: Lipopolysaccharide: Resveratrol: PUFA

Localised inflammation that is considered a protective reaction to tissue irritation, injury or infection can also be involved in several pathologies ${ }^{(1-3)}$. Macrophages are considered to play a major role in the body's response to immunogenic challenges, by re-establishing tissue homeostasis, producing large amounts of reactive oxygen species, NO and proinflammatory cytokines, which aggravate and propagate local inflammation and disrupt the normal function of target cells $^{(4)}$. In fact, previous studies performed in RAW 264.7 murine macrophage cells have shown the importance of macrophages in enhancing inflammation by secreting pro-inflammatory factors, such as TNF- $\alpha$ and IL- $1 \beta^{(5)}$.

Multiple mechanisms can propagate inflammation. Some pathways in the cell can modulate inflammation through phosphorylation cascades of proteins that translocate to the nucleus to induce the expression of inflammation genes.
One of the more important cascades is the NF-кB pathway. The currently known subunit members of the NF-кB family in mammals are p50, p65 (RelA), c-Rel, p52 and RelB. Moreover, NF-кB inhibitor (Iк-B) has multiple mammalian forms, such as I $-\mathrm{B} \alpha, \beta, \gamma(\mathrm{p} 105), \delta$ (p100) and $\varepsilon$ as well as Bcl-3. In unstimulated cells, canonic NF- $\mathrm{B}$ dimeric protein $(\mathrm{p} 50$ and $\mathrm{p} 65$ ) is bound in the cytoplasm to Iк-B $\alpha$, and upon stimu-

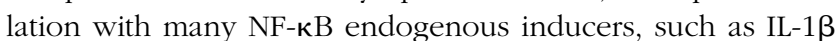
and TNF- $\alpha$, or potent exogenous inducers, such as lipopolysaccharide (LPS), I $\mathrm{K}-\mathrm{B} \alpha$ is rapidly phosphorylated by I $\mathrm{-B}$ kinases (IKK) and is marked for ubiquitination and degradation in the cytoplasm. The released NF-кB dimer can be activated by $\mathrm{p} 65$ phosphorylation and then translocated to the nucleus where NF- $\mathrm{B}$ will trigger the transcription of target genes by binding with high affinity to $\kappa \mathrm{B}$ elements in their promoters ${ }^{(6-8)}$.

Abbreviations: AP-1, activator protein 1; EGCG, epigallocatechin gallate; Ік-B, NF-кB inhibitor; IKK, Ік-B kinases; LPS, lipopolysaccharide; MAPK, mitogen-activated protein kinase; Mmp, matrix metalloprotease; NOP, NO production; Res, resveratrol; P-SAPK/JNK, phospho-stress activated protein kinase/Jun N-terminal kinase.

*Corresponding author: M. Blay, fax +34 977558232, email mteresa.blay@urv.cat 
Other pathways are implicated in inflammation, and include molecular partners, such as the transcription factor activator protein 1 (AP-1). When an extracellular stimulus arrives at the cell membrane, specific toll-like receptors activate complex signalling cascades, including the three major mitogen-activated protein kinase (MAPK) signalling pathways, namely, the extracellular-signal-regulated kinase, the SAPK/ JNK and p38 pathways. These MAPK activate the transcriptional activity of AP-1 proteins, such as FBJ murine osteosarcoma viral oncogene homologue (FOS) and V-junavian sarcoma virus 17 oncogene homologue (JUN), by phosphorylation and then, translocate to the nucleus, induce the expression of several inflammation target genes, such as Tnf- $\alpha$ and $I l-1 \beta$, and genes implicated in matrix degradation, such as matrix metalloprotease $(M m p)^{(9,10)}$.

In this context, several food compounds could help to decrease inflammation associated with disease states by modulating the expression of proteins related to these pathways. Polyphenols are an extensive molecule family that have well-known antioxidant properties and are widely distributed in foods, such as cereals, fruits, vegetables and beverages. In addition, these molecules have anti-inflammatory, antitumour and antiatherogenic abilities ${ }^{(11)}$. These effects are related to free-radical scavenging, NO regulation, leucocyte immobilisation, apoptosis induction, inhibition of cell proliferation and angiogenesis, antilipid peroxidation, inhibition of inflammatory cytokine production, alterations in cell membrane receptors, intracellular signalling pathway proteins and modulation of gene expression ${ }^{(12,13)}$. All of these effects may contribute to their potentially protective role in inflammatory and CVD ${ }^{(12,14)}$.

One important polyphenol is epigallocatechin gallate (EGCG; Fig. 1), that belongs to the flavan-3-ol group, and is present mostly in tea leaves and in green tea. It has been reported that EGCG possesses the ability to inhibit the activation of transcription factors, such as NF- $\kappa \mathrm{B}$ and $\mathrm{AP}-1^{(15)}$, and mRNA expression levels of proinflammatory cytokines, such as TNF- $\alpha$, in macrophage RAW 264.7 cells $^{(16)}$

On the other hand, resveratrol (Res; trans-3,5,49-trihydroxystilbene, Fig. 1), that belongs to the stilbenes group, is present in dark-coloured grapes ${ }^{(14,17)}$, mulberries, peanuts and red wines, and it has been known as an anti-inflammatory and antioxidant agent in studies performed in vitro and in vivo. In addition, Res is known to inhibit the transcription of proinflammatory genes and to modulate the action of transcription factors, such as NF- $\mathrm{BB}$ or $\mathrm{AP}-1$, in mouse and human cells ${ }^{(18-21)}$.

Other bioactive compounds that can ameliorate inflammation are PUFA. EPA and DHA (Fig. 1) are long-chain $n$-3 PUFA that are present mainly in fish oils and marine products, such as tuna, cod, sardine or salmon ${ }^{(22)}$. It has been demonstrated that these molecules possess several beneficial properties for human CVD and inflammatory disease. These biological effects are related to lipoprotein metabolism, endothelial cell function, vascular reactivity, inflammatory markers and cytokine production $^{(23,24)}$. Most of these beneficial effects are due to their antioxidant and anti-inflammatory effects by decreasing reactive oxygen species ${ }^{(25)}$ and by decreasing the generation of proinflammatory cytokines, like TNF- $\alpha$, IL-1 $\beta$ and IL-6, leading to the deactivation of the NF- $\mathrm{B}$ signalling cascade and the activation of the PPAR $\gamma$ anti-inflammatory pathway ${ }^{(26)}$.

The present study assessed whether polyphenols EGCG and Res, and PUFA, DHA and EPA, can modulate the expression of inflammatory genes and proinflammatory proteins and whether polyphenols and PUFA have enhancer anti-inflammatory effects at different levels on murine macrophages stimulated with LPS to induce inflammation. Furthermore, this study aimed to define the individual antiinflammatory role of these bioactive compounds.<smiles>O=C(O[C@H]1Cc2c(O)cc(O)cc2OC1c1cc(O)c(O)c(O)c1)c1cc(O)c(O)c(O)c1</smiles>

(a)<smiles>Oc1ccc(C=Cc2cc(O)cc(O)c2)cc1</smiles>

(d)

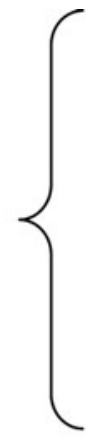<smiles>Oc1cc(O)c2c(c1)OC(c1cc(O)c(O)c(O)c1)[C@H](O)C2</smiles>

(b)<smiles>O=C(O)c1cc(O)c(O)c(O)c1</smiles>

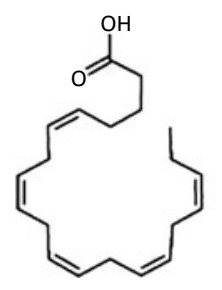

(e)

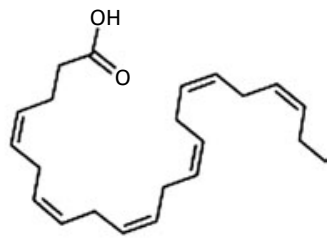

(f)

Fig. 1. Molecular structure of polyphenols ((a) epigallocatechin gallate, (b) epigallocatechin, (c) gallic acid and (d) resveratrol) and PUFA ((e) EPA (20:5n-3) and (f) DHA (22:6n-3)). 


\section{Experimental methods}

\section{Reagents and cells}

The following chemicals were purchased from Sigma-Aldrich:

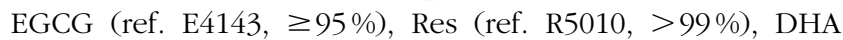
(ref. D2534, $\geq 98 \%$ ), EPA (ref. E2011, $\geq 99 \%$ ) and LPS from Escherichia coli 0111: B4 (ref. L4391, lot: 127K4037).

The murine macrophage cell line RAW 264.7 (ref. 91062702; European Tissue Culture Collection ECACC) was cultured at $37^{\circ} \mathrm{C}$ under $5 \% \mathrm{CO}_{2}$ in Dulbecco's modified Eagle's medium containing $10 \%(\mathrm{v} / \mathrm{v})$ fetal bovine serum, $2 \mathrm{~mm}$-D-glutamine, penicillin $(100 \mathrm{U}(62.7 \mu \mathrm{g}) / \mathrm{ml})$, streptomycin $(100 \mu \mathrm{g} / \mathrm{ml})$ and 25 mm-HEPES. The cells were between ten and sixteen passages when they were treated.

\section{Experimental design}

For all the experiments, RAW 264.7 cells were cultured in twelve-well plates. At 80-90\% confluency, the medium was replaced with a colourless Dulbecco's modified Eagle's medium with antibiotics and without fetal bovine serum, and was then treated depending on the experiment. Previously, the administration in cells, EPA and DHA were diluted in colourless Dulbecco's modified Eagle's medium with bovine serum albumin NEFA with a ratio of 1:4 (PUFA:bovine serum albumin), and EGCG and Res in PBS. The final concentrations of compounds were the following in all the experiments: EGCG and Res $(2.5 \mu \mathrm{g} / \mathrm{ml})$, and DHA and EPA $(30 \mu \mathrm{m})$.

For the NO production (NOP) experiment, a total of eight conditions were tested: $\mathrm{C}-$ (only vehicle, $\mathrm{PBS}+$ ethanol), C+ (LPS $100 \mathrm{ng} / \mathrm{ml})$, EGCG, Res, DHA, EPA, EGCG + DHA, Res + DHA, EGCG + EPA, Res + EPA. Cells were stimulated with LPS $(100 \mathrm{ng} / \mathrm{ml})$ and co-incubated with polyphenols and PUFA and after $19 \mathrm{~h}$ of treatment, the medium was collected and stored at $-20^{\circ} \mathrm{C}$.

For the phosphoprotein immunoassay, the following conditions were used (three wells/condition): medium only with vehicle, LPS, Res + LPS, EPA + LPS, and Res + EPA + LPS. After $30 \mathrm{~min}$ of co-incubation, the medium was collected and stored at $-80^{\circ} \mathrm{C}$.

For the TaqMan ${ }^{\circledR}$ Low-density Array assay, the following conditions were used (three wells/condition): medium only with vehicle, LPS, Res + LPS, EPA + LPS and Res + EPA + LPS. After $19 \mathrm{~h}$ of treatment, the medium was collected and stored at $-80^{\circ} \mathrm{C}$. The cells were counted with a Countess ${ }^{\circledR}$ Automated Cell Counter (ref. C10227; Invitrogen) with a final average of $1.2 \times 10^{6}$ live cells $/ \mathrm{ml}$, and a viability of $93 \%$.

\section{Testing the capacity of polyphenols and PUFA alone and} in combination for suppressing nitric oxide production in RAW 264.7 cells

To analyse the putative effect of polyphenols and PUFA alone or in combination, NOP was determined by the Griess reagent, which reacts with the $\mathrm{NO}_{2}^{-}$ion to produce a final stable product that is purple and can be quantified using colorimetric or spectrophotometric techniques at $540 \mathrm{~nm}^{(17)}$. Nitrite production was normalised to protein content using
$0 \cdot 1 \mathrm{M}-\mathrm{NaOH}$ for the cell lysate and the Bradford method (ref. B6916; Sigma-Aldrich). The assays were performed in technical and biological triplicate. The results are represented as the percentage of NOP $v$. that produced by the cells stimulated with LPS $(\mathrm{C}+)$.

\section{Immunoassay of phosphoproteins using Pathscan ELISA kit}

To assess the levels of several phosphoproteins that are able to activate inflammation in macrophages, a multi-target ELISA kit was used. The PathScan ${ }^{\circledR}$ Inflammation Multi-Target Sandwich ELISA Kit (ref. 7276) was provided by Cell Signaling.

After treatment, the adherent monocytes were washed with ice-cold PBS, and then the 1X Cell Lysis Buffer (ref. 9803; Cell Signaling) + 1 mm-phenylmethylsulphonyl fluoride were added. The plate was incubated for $5 \mathrm{~min}$ on ice. The cells were scraped and transferred to a tube, and each lysate was sonicated for $10 \mathrm{~s}$ using a Vibra-Cell VCX 750 Sonicator (Sonics and Materials, Inc.). The lysates were centrifuged at $11000 \mathrm{~g}$ for $10 \mathrm{~min}$ at $4^{\circ} \mathrm{C}$, and the supernatant was stored in a new tube at $-80^{\circ} \mathrm{C}$ until assay day. The protein content of the lysates was determined by the Bradford method (SigmaAldrich) to readjust all of the samples to $5 \mathrm{mg} / \mathrm{ml}$ of protein. Phosphoproteins P-NF-кB p65 (Ser536), P-SAPK/JNK (Thr13/ Tyr185), P-p38 (Thr180/Tyr182), P-IкB- $\alpha$ (Ser32) and P-STAT3 (Tyr705; phospho-Signal transducer and activator of transcription 3) as well as NF- $\mathrm{B}$ p 65 were semi-quantified using the PathScan ${ }^{\circledR}$ Inflammation Multi-Target Sandwich ELISA Kit. Briefly, the lysates were diluted with a sample diluent and were added to the appropriate well that contained its relevant antibody adhered at the bottom. The plate was incubated overnight at $4{ }^{\circ} \mathrm{C}$, and the wells were washed with washing buffer four times. Then, detection or primary antibody was added to the appropriate well, and the plate was incubated for $1 \mathrm{~h}$ at $37^{\circ} \mathrm{C}$. After a second washing of four times, the horseradish peroxidase (HRP)-linked secondary antibody was added, and the plate was incubated for $30 \mathrm{~min}$ at $37^{\circ} \mathrm{C}$. The $3,3^{\prime}, 5,5^{\prime}$-tetramethylbenzidine (TMB) substrate was added to each well, and the plate was incubated for $30 \mathrm{~min}$ at room temperature. Finally, the reaction was stopped and the samples were read at an absorbance of $450 \mathrm{~nm}$ in an ELISA spectrophotometer (Anthos Zenyth 200 st; Anthos Labtec Instruments). The assay was performed in technical duplicate. Each phosphoprotein absorbance was corrected by the negative control and was normalised by its relevant NF-кB p65 absorbance. The results were expressed as the percentage of phosphoprotein absorbance $v$. that produced by cells just stimulated with LPS.

\section{TaqMan ${ }^{\circledR}$ Low-density Array gene expression analysis}

To make screening of numerous genes implicated in inflammation, oxidative stress and other metabolic mechanisms, a TaqMan ${ }^{\circledR}$ Low-density Array was used. The RNeasy Mini Kit (ref. 74106; Qiagen) was used according to the manufacturer's instructions to isolate RNA from pretreated RAW cells. After collecting the medium, ice-cold PBS was added to the adherent monocyte cells. Then, the PBS was removed, and lysis buffer was added to each well. After several centrifugations 
and washings, the RNA was diluted with $50 \mu$ l of RNase-free water. RNA purity and quantity were measured with the Nanodrop 1000 (Thermo Fisher Scientific), and RNA integrity was checked with the Agilent 2100 Bioanalyzer (ref. G2938C) using the Agilent RNA 6000 Nano Kit (ref. 5067-1511; Agilent Technologies). Finally, the RNA was stored at $-80^{\circ} \mathrm{C}$. Next, complementary DNA was synthesised from $2 \mu \mathrm{g}$ of total RNA using the High-Capacity cDNA Reverse Transcription Kit (ref. 4368814; Applied Biosystems), diluted to $100 \mathrm{ng} / \mu \mathrm{l}$ of complementary DNA to load into each reservoir of the TaqMan ${ }^{\circledR}$ Low-density Array (array on demand; Applied Biosystems). Each TaqMan ${ }^{\circledR}$ Low-density Array plate (96a format), which contains sets of ninety-six mouse gene probes and mouse primers (ninety genes + five controls), was analysed using a realtime PCR amplification system with the Taqman Universal PCR Master Mix (Applied Biosystems). These genes are related to different biological functions and were organised into twelve categories: (1) cytokines $30 \cdot 2 \%$ of the total number of genes analysed) including members of the TNF family (5.2\%), IL and IL receptors (15.6\%), and chemokines and chemokine receptors $(8.3 \%)$; (2) transcription factors and regulators (16.7\%); (3) MAPK signalling cascade proteins (6.3\%); (4) oxidative stress components $(10 \cdot 4 \%)$; (5) scavenger receptors and cholesterol efflux channels (8.3\%); (6) adhesion molecules ( $2 \cdot 1 \%)$; (7) apoptosis proteins ( $2 \cdot 1 \%)$; (8) proinflammatory proteins $(5 \cdot 2 \%)$; (9) matrix degradation and regulatory proteins $(2 \cdot 1 \%)$; (10) proteins involved in metabolism (5.2\%); (11) monocyte markers (5.2\%); (12) binding proteins (1.0\%). The 7900HT Fast Real-Time PCR with 384-Well Block Module and the 7900 HT Sequence Detection System software (SDS 2.3) (Applied Biosystems) were used to perform realtime PCR and subsequent analysis of the results.

\section{Calculating the potentiating effects of the molecules in combination}

To evaluate the enhancer effects of the compounds in combination, we considered the following:

Percentage of maximum inhibition of compounds alone in medium

$$
\begin{aligned}
& \mathrm{X} \text { : (\% NOP in positive control } \\
& \quad-\% \text { NOP of compound ' } \mathrm{X} \text { ' alone }+\mathrm{SEM}) \\
& \mathrm{Y} \text { : (\% NOP in positive control } \\
& \quad \text { - \% NOP of compound ' } \mathrm{Y} \text { ' alone + SEM). }
\end{aligned}
$$

Percentage of minimum inhibition of compounds together in medium

$$
\begin{aligned}
(\mathrm{X}+\mathrm{Y}): & (\% \text { NOP in positive control } \\
& -\% \text { NOP of compounds ' } \mathrm{X} \text { ' and ' } \mathrm{Y} \text { ' together }-\mathrm{SEM}) .
\end{aligned}
$$

If $\mathrm{X}+\mathrm{Y}$ is less than or equal to $(\mathrm{X}+\mathrm{Y})$, there is an enhanced anti-inflammatory effect. If $\mathrm{X}+\mathrm{Y}$ is greater than $(\mathrm{X}+\mathrm{Y})$, there is an enhanced proinflammatory effect.

Both compounds had to have a significant NOP individually compared with the NOP when combined. If one of the compounds alone did not fulfil these criteria, we concluded that the compounds would not have an effect when combined.
These criteria were also used to evaluate the effects on phosphoprotein and gene expression levels.

We also used one of the most cited, recommended and accepted models for defining drug interactions in order to assess if our enhancer effects could be considered synergistic, additive or antagonistic: The Bliss independence model ${ }^{(27-29)}$. This model is also called effect multiplication or the fractional product, which has the form $E_{(12)}=E_{(1)} \times E_{(2)}$, where $E_{(12)}$ is the effect of the compounds in combination expressed as a fraction, and $E_{(1)}$ and $E_{(2)}$ are the effects for compound 1 and compound 2 expressed as fractions. Combination doses with effects less than that predicted are synergistic, with effects equal are additive and with effects greater are antagonistic. However, this consideration can only be claimed using the Loewe model ${ }^{(28,29)}$, which refers to the combinatorial study of drugs performing isobolographic analysis; so that the interpretation of our results using the Bliss method must be qualified as a precursor of new studies that reassert these effects.

\section{Statistical analysis}

The results are presented as means with their standard errors. The data were analysed by one-way ANOVA to determine the statistical differences between groups using SPSS statistical software (version 17.0 for Windows; SPSS, Inc.). $P<0.05$ was considered statistically significant.

\section{Results}

\section{Effects of polyphenols and PUFA suppressing nitric oxide production in stimulated RAW cells}

LPS is a well-known trigger of the inflammation response in macrophages, and several biomarkers, like NO, can be tested to measure this response. RAW 264.7 macrophages were stimulated with LPS for $19 \mathrm{~h}$, and NOP was determined. Macrophages in the positive control medium had a mean NOP of $37.7 \mu \mathrm{M}$. To examine the synergistic effects in suppressing the NO, polyphenols Res and EGCG were tested using $2.5 \mu \mathrm{g} / \mathrm{ml}$ doses and the PUFA, DHA and EPA, were tested using $30 \mu \mathrm{M}$ doses. These doses and time were chosen on the basis of dose-response and time-course experiments in RAW 264.7 macrophages stimulated with LPS as a positive control to check the inhibition of NO at different concentrations of the compounds ${ }^{(21,25,30)}$ (see supplementary Figs. S6 and S7 available online at http://www.journals.cambridge.org/bjn). The molecules are non-toxic in RAW 264.7 macrophages at least below the following concentrations: Res $22.82 \mu \mathrm{g} / \mathrm{ml}$, EGCG $4 \cdot 58 \mu \mathrm{g} / \mathrm{ml}$, EPA $100 \mu \mathrm{M}$, DHA $100 \mu \mathrm{M}^{(25,31,32)}$.

In these conditions, an enhancer effect was found when Res was combined with EPA (Fig. 2(B)). The treatment with EPA significantly inhibited NOP $v$. the positive control $(-45.0 \%$ of NOP, Fig. 2(B)), while Res did not inhibit it at the tested concentration $(+8.5 \%$ of NOP, Fig. 2(B)). In spite of this, the combination of these compounds had a stronger inhibition than Res or EPA individually ( $-83.6 \%$ of NOP, Fig. 2(B)) Besides, using the Bliss model $\left(E_{(12)}=E_{(1)} \times E_{(2)}\right)$, we found that $E_{(12)}$ was 0.164 , less than $E_{(1)} \times E_{(2)}$ that was 0.597 $(\operatorname{Res} \times \mathrm{EPA}=1.085 \times 0.55)$, which signifies a synergistic 
effect. In addition, another strong inhibitory effect was found when Res and DHA were combined $(-33.7 \%$ of NOP; Fig. 2(B)), with their effect being significantly different compared to DHA ( $-20 \cdot 6 \%$ of NOP, Fig. 2(B)) and Res $(+8.5 \%$ of NOP, Fig. 2(B)) alone and classified as a synergistic effect using the Bliss model, with $E_{(12)}=0.663$ being less than $E_{(1)} \times E_{(2)}=0.861(\operatorname{Res} \times \mathrm{DHA}=1.085 \times 0.794)$. In contrast, EGCG alone did not inhibit NOP significantly $v$. positive control ( $-14.3 \%$ of NOP; Fig. 2(A)), and the combination with EPA had the same effect than EPA alone $(-45 \%$ of NOP; Fig. 2(A)).

\section{Effect of resveratrol in combination with EPA in suppressing phosphoprotein levels in stimulated RAW macrophages}

To measure the levels of several proteins involved in inflammatory pathways, PathScan ${ }^{\circledR}$ Inflammation Multi-Target Sandwich ELISA was used. These proteins, which reside in the cytoplasm, are phosphorylated by other proteins in the phosphorylation cascade that is induced by an external inflammatory agent, like LPS, and lead to the activation of
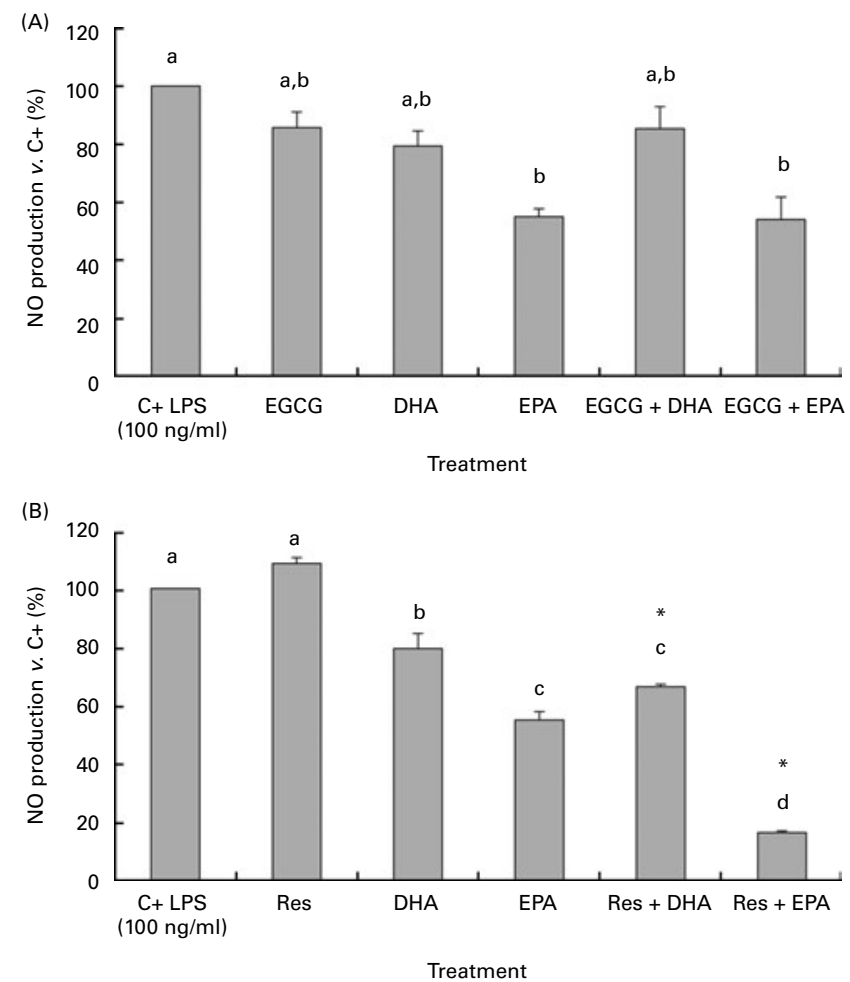

Fig. 2. The effects of polyphenols (epigallocatechin gallate (EGCG) and resveratrol (Res); $2.5 \mu \mathrm{g} / \mathrm{ml}$ ) and PUFA (DHA and EPA; $30 \mu \mathrm{M}$ ) on nitric oxide production in RAW 264.7 macrophages stimulated with lipopolysaccharide (LPS; $100 \mathrm{ng} / \mathrm{ml}$ ). The results are presented as the percentage of nitric oxide production and normalised to the positive control (100\%). Values are means with their standard errors of biological and technical triplicates. a,b,c,d Mean values with unlike letters were significantly different and the symbol * signifies enhanced effect. For all of the comparisons, a one-way ANOVA with post hoc test was used, with $P<0.05$ as the threshold for statistical significance. The values of EPA and DHA represented in (A) and (B) are the same, but were included in both because they were necessary for the statistical analysis with the other groups. proteins that modulate gene transcription in the nucleus. The phosphorylated proteins, P-NF-кB p65, P-SAPK/JNK, P-p38, P-IкB- $\alpha$ and P-STAT3, were tested. RAW 264.7 macrophages were stimulated with LPS $(100 \mathrm{ng} / \mathrm{ml})$ for $30 \mathrm{~min}$ to detect phosphoprotein levels in these conditions ${ }^{(33-37)}$. At the same time, different concentrations of the following compounds were applied to different groups of cells: Res $(2 \cdot 5 \mu \mathrm{g} / \mathrm{ml})$, EPA $(30 \mu \mathrm{M})$ and Res + EPA $(2.5 \mu \mathrm{g} / \mathrm{ml}, 30 \mu \mathrm{M})$. These assays revealed an enhancer effect on P-SAPK/JNK protein (Fig. 3(B)). The absorbance level of P-SAPK/JNK in Res-treated and EPA-treated cells was decreased significantly compared with the positive control $(-13 \%$ of P-SAPK/JNK level, Fig. 3(B)). In addition, when the cells were treated with a combination of Res and EPA, P-SAPK/JNK level had a stronger decrease than Res or EPA separately $(-30.8 \%$ of P-SAPK/JNK level, Fig. 3(B)). Although many treatments were statistically significant compared with the positive control, no more enhancer effects were found in P-NF-кB p65 (Fig. 3(A)), P-p38 (Fig. 3(C)), P-STAT3 (Fig. 3(D)) and P-IкB- $\alpha$ levels (Fig. 3(E)).

\section{Effect of resveratrol in combination with EPA in modulating the expression of pro-inflammation target genes in stimulated RAW macrophages}

RAW 264.7 macrophages were stimulated with LPS (100 ng/ml) for $19 \mathrm{~h}$ to trigger the expression of several target genes involved in inflammation, oxidative stress and metabolism pathways. Cells were treated with LPS alone (positive control) or LPS and Res, EPA or Res and EPA to measure the inhibition of proinflammatory genes. The most important enhanced effects of Res and EPA are shown in Table 1, whereas the rest of the results are in Table S2 (available online at http:// www.journals.cambridge.org/bjn). We considered that the genes were up-regulated or down-regulated if they had significant differences $v$, the negative and/or positive control groups. We found that LPS treatment led to a greater than 100 -fold increase in the expression of $\mathrm{Il}-1 \alpha, \mathrm{Il}-1 \beta, \mathrm{Il}-6, \mathrm{Ccl} 7$ and $C s f 2$ and more than a 10 -fold increase in the expression of Tnfrsf1b, Il-10, Il-1rn, Il-12ß, Ccl2, Ccl5, Timp1, Nos2, Ptgs2, Serpine1, Socs 2 and Socs 3 genes. Most of these genes have important proinflammatory and anti-inflammatory functions. Thus, we found LPS-mediated gene regulation that seems to follow an inflammatory profile ${ }^{(38-41)}$. Moreover, we found different profiles of the regulation of anti-inflammatory, antioxidant and proinflammatory genes depending on the treatment administrated (Figs. 4 and 5), showing that the treatment of Res + EPA had a stronger anti-inflammatory profile than Res or EPA individually. Specifically, treatment with Res increased significantly the levels of Il-2 receptor, $I l-2 r \alpha$, the kinase inhibitor of $N f$ - $\mathrm{b}$, Ikk- $\beta$, Tnfrsf 18 and Socs3, and decreased significantly proinflammatory genes, such as Fas, $I l-1 \beta, C c l 2$, Socs 2 , or the proto-oncogene $M y c$. In addition, other proinflammatory genes, such as $I l-1 \alpha, I l-6, \operatorname{Cs} f 2, \operatorname{Nos} 2$, Ptgs 2 and Mmp9, had a tendency to decrease their levels in comparison to the positive control. In contrast, treatment with EPA increased the proinflammatory Fas, Ccl3, Tnfrsf18 and Msr1 genes, the anti-inflammatory Il-1rn, Nfkbia and 
Socs 3 genes, and the antioxidant Hmox1, Cat and Gclm genes. In addition, EPA treatment decreased the proinflammatory Tnf- $\alpha, I l-2 r \alpha$ and $I l-12 \beta$ genes. Treatment with Res and EPA increased the gene expression of $I l-12 \beta, H m o x 1$ and Cat, and decreased $\mathrm{Il}-1 \beta, \mathrm{Il}-6, \mathrm{Il}-23 \mathrm{a}$, Serpine1, Nos2, Il-2r $\alpha, \mathrm{Il}-10$ and Nfkbia in comparison to positive control. In addition, we found an enhancer effect in the inhibition of the expression of proinflammatory genes, including Tnf- $\alpha$, Tnfrsf18, Csf2, Ccl2, Ccl5, Nf-кb P65, Ikk- $\beta$, Map3k8 and Mapk8, and, surprisingly, the anti-inflammatory Tnfrsf $1 b$, Hdac2, Socs 2 and Socs 3 genes. We also found a potentiating effect in the inhibition of the expression of a stress-inducible chaperone protein, Hspa5.

\section{Discussion}

An interesting area in functional food science is discovering the enhancer effects or synergies between bioactive components to create foods that have improved health benefits. Such an investigation would require studies with in vitro and in vivo models. Our work is the first step in achieving these goals.

Macrophages, which play an important role in the inflammatory states of several tissues and various diseases, can help us to understand how polyphenols and PUFA modulate local inflammation at different biological levels. Thus, we stimulated murine RAW 264.7 macrophages with LPS to mimic this inflammatory state and study the synergistic effects of these natural compounds.

Important enhanced anti-inflammatory effects were found when Res at $2.5 \mu \mathrm{g} / \mathrm{ml}+\mathrm{EPA}$ at $30 \mu \mathrm{m}$ were in combination. It has been reported that a study of forty-eight subjects consuming fish once or twice a month had a detectable plasma DHA level of about $60 \mu \mathrm{g} / \mathrm{ml}$ and EPA of about $10 \mu \mathrm{g} / \mathrm{ml}$, which is equivalent to 182 and $33 \mu \mathrm{M}$, respectively ${ }^{(25)}$. Therefore, our tested concentrations of PUFA are close to the bioavailability levels found in plasma of these studies in vivo. In contrast, several studies in human subjects and rats are in controversy regarding the bioavailability of Res in blood plasma, with some studies reporting that this is between $1 \times 10^{-3}$ and $9 \times 10^{-3} \mu \mathrm{g} / \mathrm{ml}^{(42,43)}$, while the others reporting that it is $1.2 \mu \mathrm{M}(0.273 \mu \mathrm{g} / \mathrm{ml})^{(44)}$, being the free-Res form that is very low in plasma in comparison with their metabolised forms (derivated glucuronides and sulphates) generated in the intestine and the liver before being delivered to the systemic circulation $^{(45)}$. However, pharmacokinetic studies in human subjects, following the oral administration of $2 \mathrm{~g}$ of Res twice daily, obtained a plasma concentration of 1274 (SEM 790) $\mathrm{ng} / \mathrm{ml}$ of free-Res ${ }^{(46)}$, which is not very far from our tested dose of $2.5 \mu \mathrm{g} / \mathrm{ml}$ Res. Despite this, our tested concentration is far from being physiological and the concentration might be adjusted to $\mathrm{ng} / \mathrm{ml}$ to confirm, in new future experiments, the enhancer effect of Res in combination with PUFA at physiological levels. Also, combinatorial studies may be performed with these molecules in order to assess if these enhanced effects can be considered as synergistic.

First, we tested whether polyphenols and PUFA can inhibit NOP, a clear marker of inflammation in macrophages.
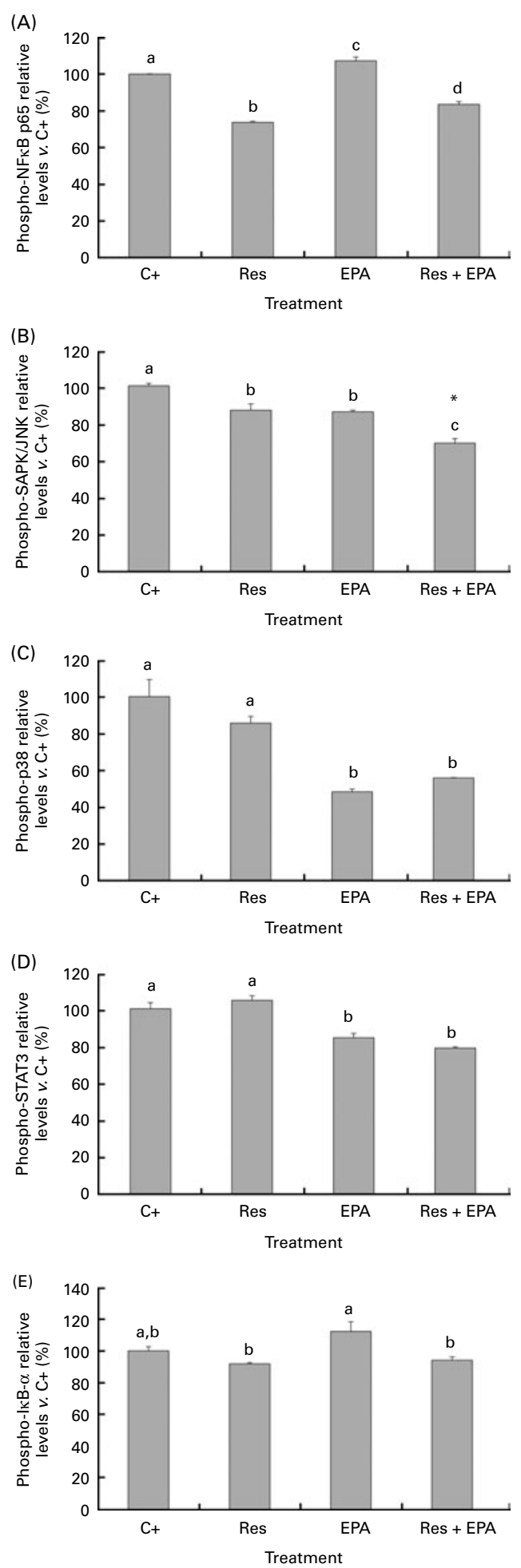

Fig. 3. The effects of resveratrol (Res; $2.5 \mu \mathrm{g} / \mathrm{ml})$ and EPA $(30 \mu \mathrm{M})$ on the levels of (A) phospho-NFKB p65, (B) phospho-stress activated protein kinase/Jun N-terminal kinase (phospho-SAPK/JNK), (C) phospho-p38, (D) phospho-STAT3 and (E) phospho-IкB- $\alpha$ in RAW 264.7 stimulated with lipopolysaccharide $(100 \mathrm{ng} / \mathrm{ml})$. The results are presented as the percentage of relative levels of phosphoproteins and are normalised to the positive control $(100 \%)$. Values are means with their standard errors of technical duplicates. ${ }^{\mathrm{a}, \mathrm{b}, \mathrm{c}, \mathrm{d}}$ Mean values with unlike letters were significantly different and the symbol * signifies enhanced effect. For all of the comparisons, a one-way ANOVA with post hoc test was used, with $P<0.05$ as the threshold for statistical significance. 
Table 1. The most important effects of resveratrol (Res; $2.5 \mu \mathrm{g} / \mathrm{ml}$ ) and EPA (30 $\mu \mathrm{M})$ on the expression of twenty-seven genes in RAW 264.7 macrophages stimulated with lipopolysaccharide (LPS; $100 \mathrm{ng} / \mathrm{ml})^{*}$

(Mean values and standard deviations)

\begin{tabular}{|c|c|c|c|c|c|c|c|c|c|c|}
\hline \multirow[b]{3}{*}{ Gene function } & \multirow[b]{3}{*}{ Gene symbol } & \multirow[b]{3}{*}{ Gene name } & & & \multicolumn{6}{|c|}{ LPS + molecules } \\
\hline & & & \multicolumn{2}{|c|}{ LPS } & \multicolumn{2}{|c|}{ Res } & \multicolumn{2}{|c|}{ EPA } & \multicolumn{2}{|c|}{ Res + EPA } \\
\hline & & & Mean & SD & Mean & SD & Mean & SD & Mean & SD \\
\hline \multirow[t]{3}{*}{ TNF family } & Tnf & Tumour necrosis factor alpha & 1.62 & 0.09 & 1.60 & 0.01 & $1.40 \dagger$ & 0.01 & $1 \cdot 15 \ddagger \S$ & 0.02 \\
\hline & Tnfrsf18 & Tumour necrosis factor receptor superfamily, member 18 & 0.15 & 0.01 & $0.24 \dagger$ & 0.02 & $0.30 \dagger$ & 0.02 & $0.02 \ddagger$ & 0.00 \\
\hline & Tnfrsf1b & Tumour necrosis factor receptor superfamily, member 1B & $23 \cdot 24$ & 0.51 & 21.78 & 1.03 & 23.93 & 0.22 & $17 \cdot 38 \ddagger$ & 1.87 \\
\hline \multirow[t]{6}{*}{ IL and receptors } & $\| 1 \alpha$ & Interleukin 1 alpha & $315 \cdot 29$ & 8.42 & 281.59 & 3.64 & 289.44 & 18.91 & $252 \cdot 41$ & 33.92 \\
\hline & $I 1-1 \beta$ & Interleukin 1 beta & $280 \cdot 73$ & 1.58 & $191 \cdot 80 \|$ & $2 \cdot 16$ & 254.74 & 15.96 & 216.50\| & 0.66 \\
\hline & $\| 1-1 r n$ & Interleukin 1 receptor antagonist & 13.70 & 0.17 & 14.02 & 0.58 & $18 \cdot 11 \dagger$ & 0.20 & 14.07 & 0.35 \\
\hline & $\|-6$ & Interleukin 6 & 275.75 & $26 \cdot 35$ & 223.42 & $31 \cdot 21$ & 295.48 & $12 \cdot 23$ & $160 \cdot 62 \|$ & 13.93 \\
\hline & $11-23 a$ & Interleukin 23, alpha subunit p19 & $2 \cdot 60$ & 0.44 & 2.98 & 0.36 & $1.65 \S$ & 0.19 & $1.42 \S \|$ & 0.06 \\
\hline & $11-10$ & Interleukin 10 , cytokine synthesis inhibitory factor & 84.58 & 7.65 & $70 \cdot 35$ & $10 \cdot 46$ & 83.86 & $10 \cdot 34$ & 43.93\| & $0 \cdot 10$ \\
\hline \multirow[t]{4}{*}{ Chemokines and receptors } & Csf2 & Granulocyte-macrophage colony stimulating factor & 104.43 & 0.08 & $89 \cdot 04$ & 6.02 & 99.07 & $2 \cdot 29$ & $66 \cdot 34 \ddagger$ & 9.41 \\
\hline & $\mathrm{Ccl} 2$ & MCP-1, monocyte chemo-attractant protein 1 & 63.74 & 0.60 & $52 \cdot 62 \dagger$ & $2 \cdot 32$ & 64.44 & 1.67 & $41.36 \ddagger$ & $3 \cdot 30$ \\
\hline & $\mathrm{Ccl} 5$ & Chemokine ( $\mathrm{C}-\mathrm{C}$ motif) ligand 5 & $27 \cdot 60$ & 1.24 & 26.54 & 1.79 & 31.62 & 0.36 & $20 \cdot 74 \ddagger$ & $2 \cdot 22$ \\
\hline & $\mathrm{Ccl} 7$ & MCP-3, chemokine ( $\mathrm{C}-\mathrm{C}$ motif) ligand 7 & $126 \cdot 91$ & 2.55 & $124 \cdot 22$ & 8.40 & 138.80 & 17.46 & $90 \cdot 61$ & $10 \cdot 74$ \\
\hline \multirow[t]{6}{*}{ Transcription factors and related } & Ikbkb & IKK-beta, nuclear factor NF-kappa-B inhibitor kinase beta & 0.42 & 0.02 & $0.67 \dagger$ & 0.05 & 0.48 & 0.04 & $0.33 \ddagger$ & 0.02 \\
\hline & RelA & Nuclear factor NF-kappa-B p65 subunit & $0.72 \S$ & 0.04 & $0.78 \S$ & 0.05 & $0.71 \S$ & 0.00 & $0.53 \ddagger$ & 0.00 \\
\hline & Hdac2 & Histone deacetylase 2 & 0.45 & 0.02 & 0.47 & 0.02 & 0.52 & 0.03 & $0.34 \ddagger$ & 0.01 \\
\hline & Socs2 & Suppressor of cytokine signalling 2 & 13.48 & 0.77 & $7.49 \dagger$ & 0.51 & 13.69 & 0.68 & $1.03 \ddagger \S$ & 0.02 \\
\hline & Socs3 & Suppressor of cytokine signalling 3 & 24.52 & 0.67 & $29.59 \dagger$ & 0.40 & $33.04 \dagger$ & 0.79 & $14 \cdot 38 \ddagger$ & 0.72 \\
\hline & Serpine1 & PAI-1, plasminogen activator inhibitor 1 & 39.57 & $2 \cdot 39$ & 34.53 & 0.75 & 35.94 & 0.05 & $28 \cdot 87 \|$ & 3.06 \\
\hline \multirow{2}{*}{ MAPK and related } & Мар3k8 & Mitogen-activated protein kinase kinase kinase 8 & $1 \cdot 10 \S$ & 0.06 & $1 \cdot 19$ & 0.08 & $1 \cdot 15 \S$ & 0.03 & $0.85 \neq \S$ & 0.01 \\
\hline & Mapk8 & JNK1, stress-activated protein kinase & 0.66 & 0.04 & 0.60 & 0.04 & 0.60 & 0.03 & $0.43 \ddagger$ & 0.02 \\
\hline \multirow[t]{3}{*}{ Oxidative stress } & Hmox1 & HO-1, heme oxygenase (decycling) 1 & $9 \cdot 88$ & 0.47 & $9 \cdot 74$ & 0.66 & $18 \cdot 39 \dagger$ & 0.50 & $15.02 \dagger$ & 0.82 \\
\hline & Nos2 & iNOS, nitric oxide synthase 2 , inducible & $17 \cdot 69$ & 0.69 & 14.57 & 1.78 & $16 \cdot 26$ & 0.15 & $12 \cdot 15 \|$ & 2.06 \\
\hline & Gclm & Gamma-glutamylcysteine synthetase regulatory subunit & $0.81 \S$ & 0.04 & $0.86 \S$ & 0.02 & $1.62 \dagger$ & $0 \cdot 15$ & $1.20 \S$ & 0.12 \\
\hline Scavenger receptors & Msr1 & Macrophage scavenger receptor 1 & $1.28 \S$ & 0.00 & $1 \cdot 10 \S$ & $0 \cdot 15$ & $1.85 \S$ & 0.01 & $1.46 \S$ & 0.22 \\
\hline \multirow[t]{2}{*}{ Metabolism } & Hspa5 & $\mathrm{BiP}$, immunoglobulin heavy chain-binding protein & $3.85 \dagger$ & 0.05 & $4.62 \dagger$ & 0.00 & $2.32 \dagger$ & 0.13 & $1.76 \ddagger$ & $0 \cdot 17$ \\
\hline & Ctss & Cathepsin S & 0.38 & 0.06 & 0.40 & 0.06 & $0.60 \dagger$ & 0.06 & 0.29 & 0.01 \\
\hline
\end{tabular}

MAPK, mitogen-activated protein kinase.

*The results are presented as the relative levels of gene expression $v$. cells without treatment $(\mathrm{C}-$ ). We used the well-known mathematical equation $\delta \delta \mathrm{CT}$ to calculate these relative levels $v$. $\mathrm{C}-$. The results are presented as the means and standard deviations of technical duplicates. The statistical significance $v$. C + is represented by $\|, v$. all of the treatments by $\dagger, v$. C + and groups of compounds alone by $\ddagger$, and signifies enhanced effect. Finally, no symbol signifies statistical significance $v$. C - , while the symbol $\S$ signifies non-statistical significance $v$. C - . For all of the comparisons, a one-way ANOVA with Tukey's test was used, with $P<0.05$ as the threshold for statistical significance. 
We found that LPS stimulation at $100 \mathrm{ng} / \mathrm{ml}$ for $19 \mathrm{~h}$ can trigger NOP. This treatment is less aggressive than other treatments used previously; $1 \mu \mathrm{g} / \mathrm{ml}^{(34-37,47)}$ and $10 \mu \mathrm{g} / \mathrm{ml}^{(25,48)}$. Also, this concentration is useful for testing whether polyphenols can exert an inhibitory effect, as seen in previous studies of inflammation $^{(17)}$. In fact, we found that DHA and EPA inhibited significantly NOP $v$, the positive control as in previous studies $^{(49)}$. But, in controversy with a work performed in RAW macrophages ${ }^{(50)}$, we found that EPA had a stronger effect than DHA. It suggests that the effects of DHA and EPA depend on the doses and the time of administration. On the other hand, EGCG at $2.5 \mu \mathrm{g} / \mathrm{ml}(5.4 \mu \mathrm{M})$ had a tendency to inhibit NOP (-14.3\%) but not significantly (Fig. 2(A)), similar to a work which found an inhibition of NOP of $19 \%$ in RAW macrophages activated with $5000 \mathrm{ng} / \mathrm{ml}$ of LPS with similar concentration of EGCG, $5 \mu \mathrm{M}^{(51)}$. In contrast, Res had a similar effect to the positive control, suggesting that Res cannot inhibit NOP at $2.5 \mu \mathrm{g} / \mathrm{ml}(10.9 \mu \mathrm{M})$ (Fig. 2(B)). However, we found inhibition effects in NOP at doses 22, 44 and $66 \mu \mathrm{m}$ (5, 10 and $15 \mu \mathrm{g} / \mathrm{ml}$ of Res in supplementary Fig. S6 (available online at http://www.journals.cambridge.org/bjn), as in other studies that used similar Res concentrations ${ }^{(21,31,52)}$, suggesting that Res has intrinsic anti-inflammatory power in several conditions in RAW. When the compounds were combined, we found an enhancer effect with Res and EPA (Fig. 2(B)) and the Bliss model classified this combination as a synergy because the effect we found (0.164) was much lower than the predicted effect (0.597). These results suggest that Res and EPA could be investigated in future studies performing combination of doses between compounds and using the Loewe method to calculate synergistic effects. In this context, it suggests that while Res cannot inhibit NOP by itself, with the addition of EPA it can modulate some mechanisms that promote an even stronger inhibition of inflammation. An explanation for this result may be that EPA permits the action of Res or that Res affects the effect of EPA at cellular level, maybe because one of them could interact with the receptors of the other, increasing its effect over cells. It could also be that they use different signalling pathways leading to a final enhancer anti-inflammatory effect. In contrast, although the inhibitory effect of Res and DHA was greater than the effect of DHA and Res alone (Fig. 2(B)), using the Bliss model the effect we found (0.663) was not too far from the predicted effect (0.861), in comparison with Res and EPA results. So it suggests that the effect of this combination should be studied more to be claimed as a synergy and it must be considered as a potentiating effect. On the other hand, EGCG tended to decrease the NOP, but when combined with DHA and EPA, the inhibitory effect was not greater than the effect of the molecules alone, which suggests that EGCG cannot increase the anti-inflammatory effect of PUFA (Fig. 2(A)).

Our next aim was to determine whether Res and EPA in combination could modulate the levels of phosphoproteins implicated in inflammatory pathways, such as NF- $\mathrm{KB}$ and AP-1. We found an enhancer effect of these compounds on P-SAPK/JNK levels (Fig. 3(B)), having an inhibitor effect stronger than the molecules alone, as was seen in previous studies that reported the capacity of Res and EPA to interact with
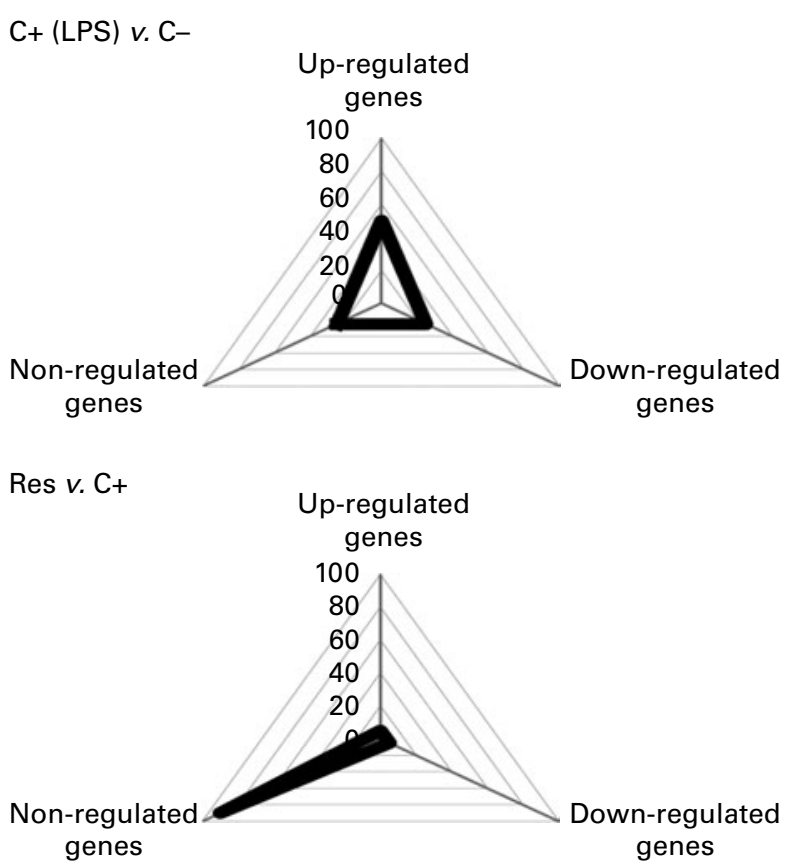

EPA $v . C_{+}$
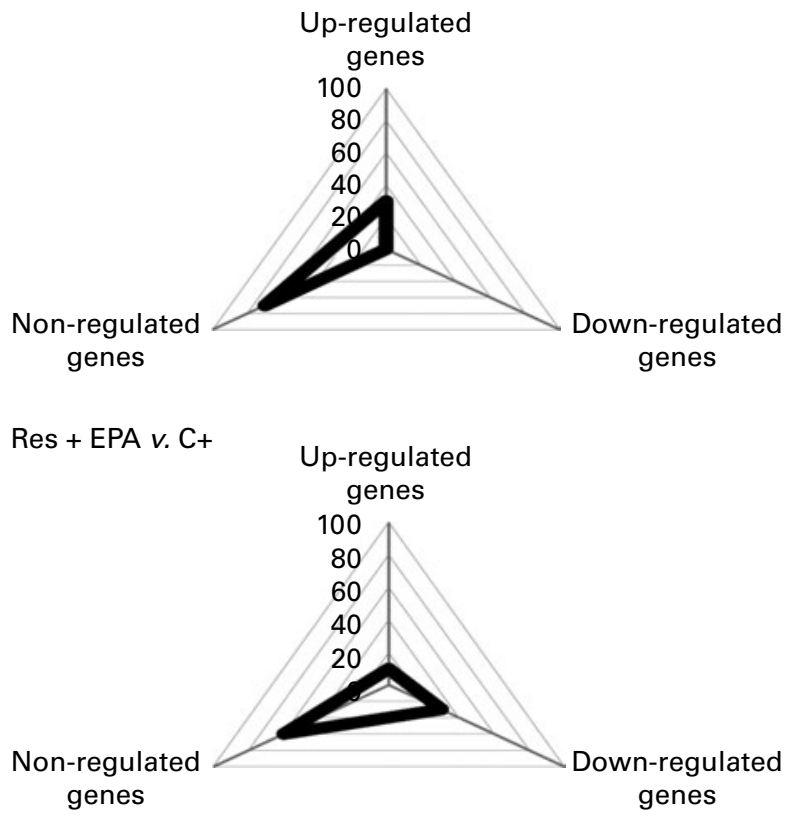

Fig. 4. The regulation $(\square)$ of proinflammatory genes in RAW 264.7 macrophages treated with lipopolysaccharide (LPS) $(\mathrm{C}+, 100 \mathrm{ng} / \mathrm{ml})$ alone or LPS and resveratrol (Res; $2.5 \mu \mathrm{g} / \mathrm{ml})$, EPA $(30 \mu \mathrm{M})$ or Res + EPA $(2.5 \mu \mathrm{g} / \mathrm{ml}$; $30 \mu \mathrm{M})$. The results are presented as the percentage of genes that were upregulated, down-regulated or not regulated with the statistical significance $v$. the control group in each title. For all of the comparisons, a one-way ANOVA with post hoc test was used, with $P<0.05$ as the threshold for statistical significance. These values were extracted from Effect of resveratrol in combination with EPA in modulating the expression of pro-inflammation target genes in stimulated RAW macrophages of this article (see Table 1 and Supplementary Table S2 (available online at http://www.journals.cambridge. org/bjn) to find out which gene is up-, down- or non-regulated for each treatment). There were thirty-eight proinflammatory genes (Tnf, Tnfrsf18,

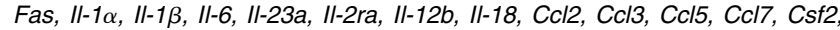
Serpine1, Jun, Ikbkb, Myc, Nfkb1, Nfkb2, RelA, Chuk, Map3k8, Map2k1, Mapk14, Mapk3, Mapk8, Nos2, Ager, Cd36, Msr1, Cd68, Acat1, Icam1, Ptgs2, Mmp9, Cd80) detected in this study. 
MAPK in macrophages ${ }^{(53,54)}$. P-SAPK/JNK inhibition may lead to the activation of the transcription factor AP-1 and may decrease the expression of proinflammatory genes, such as Tnf- $\alpha$ and $I l-1 \beta$. Thus, these molecules could attenuate the inflammatory state in cells. In addition, we found a decrease of the levels of phosphoproteins NF-кB p65, P-p38 and STAT3 when the molecules were combined (Fig. 3(A), (C) and (D)). Moreover, we found a strong decrease of P-NF-кB p65 levels when the cells were treated with Res alone (Fig. 3(A)), suggesting the high power of this molecule to affect the NF- $\kappa$ B signal pathway by itself as in other studies performed in RAW macrophages reporting the reduction of NF- $\kappa$ B activity by Res ${ }^{(21,55)}$. On the other hand, the treatment with EPA alone not only produced a slight decrease of P-SAPK/JNK and P-STAT3 levels (Fig. 3(B) and (D)), but also produced a strong decrease of P-p38 levels (Fig. 3(C)). These results suggest that EPA can modulate the phosphorylation of proteins related to proinflammatory pathways in RAW macrophages, as has been reported before ${ }^{(23,54,56)}$. However, the combination of Res and EPA had inhibitory effects on four of the five phosphoproteins assessed (P-NF-кB p65, P-SAPK/JNK, P-p38 and P-STAT3) in comparison to the $\mathrm{C}+$, while EPA had it in three (P-SAPK/JNK, P-p38 and P-STAT3) and Res just in two (P-NF- $\mathrm{B}$ p65 and P-SAPK/JNK). Thus, this result suggests that the combination has more anti-inflammatory power than either molecule alone because it can modulate more pathways than Res or EPA separately.

Our final aim was assessing whether the combination of Res and EPA had effects on the expression of genes related to inflammation and oxidative stress. As seen in the regulation profiles of proinflammatory, anti-inflammatory and antioxidant genes (Figs. 4 and 5), we found many genes that were activated in LPS-stimulated macrophages; specifically, around $50-60 \%$ of these genes were up-regulated by treatment. This result suggests that stimulation with LPS promotes an inflammatory state that has been seen in other studies ${ }^{(38-41)}$ by increasing the expression of proinflammatory target genes (Fig. 4). However, small numbers of anti-inflammatory and antioxidant genes are up-regulated as well (Fig. 5), possibly to counteract this induced proinflammatory state. Thus, the cell is in a struggle to return to fix damaged areas and return to normal. In this context, we found molecules that reverse inflammation by down-regulating proinflammatory genes and up-regulating anti-inflammatory and antioxidant genes (Figs. 4 and 5). Specifically (Table 1 and Table S2; available online at http://www.journals.cambridge.org/bjn), EPA seems to have a greater capacity for up-regulating antiinflammatory genes, such as $I l-1 r n$, which is an antagonist of the receptor for the proinflammatory IL-1 and suggests an indirect decrease in IL-1 activity, IкB- $\alpha$ (Nfkbia), which is involved in sequestering NF-кB in the cytoplasm, or Socs3, and antioxidant genes, such as Hmox1, Cat and Gclm, in charge of the destruction of reactive oxygen species, demonstrating the antioxidant ability of this molecule, as has been shown in previous works ${ }^{(49)}$. In contrast, Res has more significant effects in the down-regulation of proinflammatory genes, such as $I l-1 \beta, C c l 2$ and Fas, and non-significant effects over genes, such as $I l-1 \alpha, I l-6, C s f 2$, Serpine1, Nos2, Jun and
$\mathrm{C}+$ (LPS) vs C-

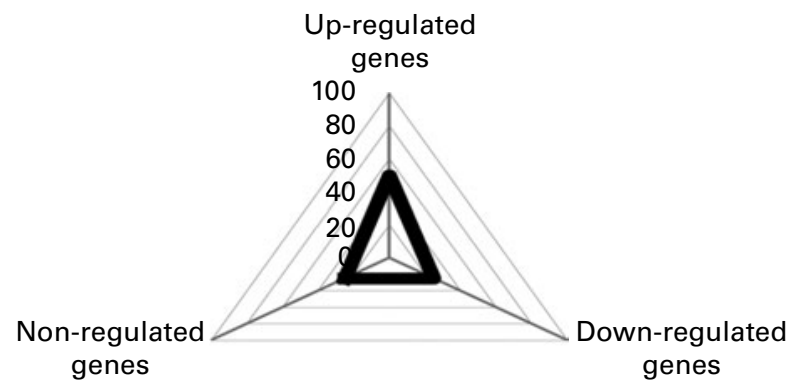

Res vs $\mathrm{C}_{+}$

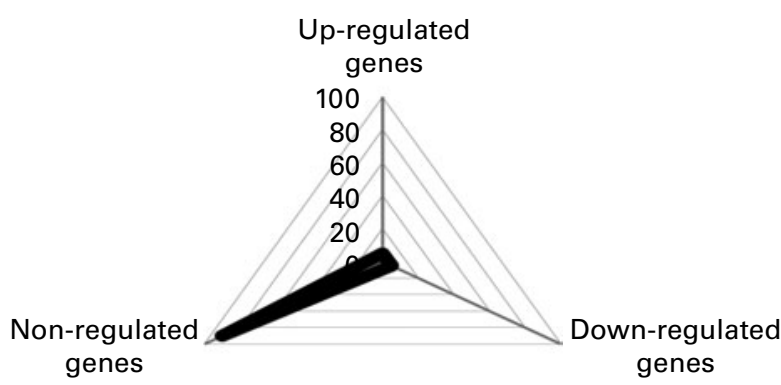

EPA vs $\mathrm{C}_{+}$

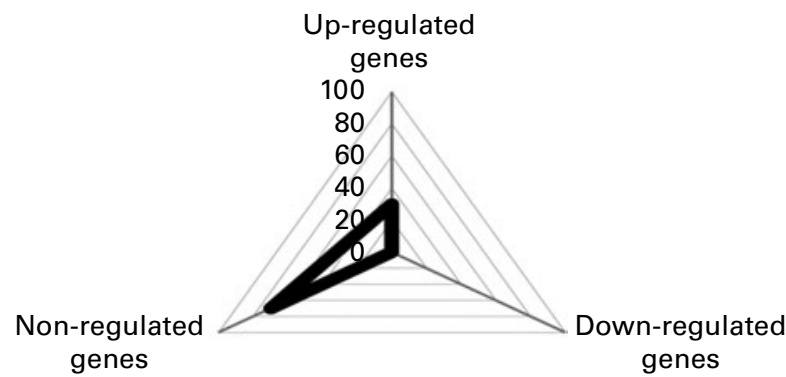

Res + EPA vs $C_{+}$

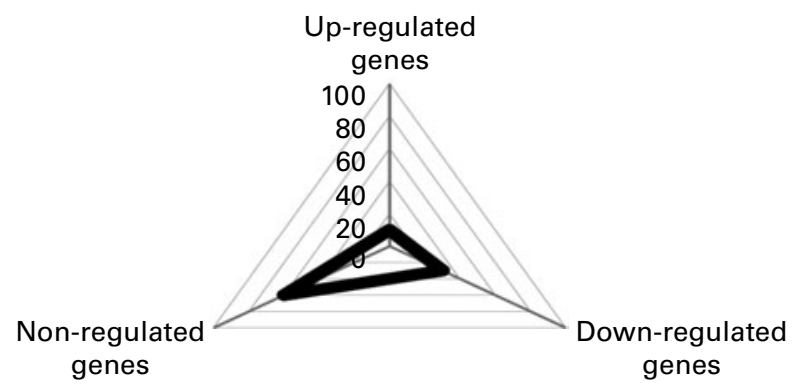

Fig. 5. The regulation ( $(\mathbf{)})$ of anti-inflammatory and antioxidant genes in RAW 264.7 macrophages treated with lipopolysaccharide (LPS) (C+, $100 \mathrm{ng} / \mathrm{ml}$ ) alone or LPS and resveratrol (Res; $2.5 \mu \mathrm{g} / \mathrm{ml})$, EPA $(30 \mu \mathrm{M})$ or Res + EPA $(2.5 \mu \mathrm{g} / \mathrm{ml} ; 30 \mu \mathrm{M})$. The results are presented as the percentage of genes that were up-regulated, down-regulated or not regulated with the statistical significance $v$. the control group in each title. For all of the comparisons, a one-way ANOVA with post hoc test was used, with $P<0.05$ as the threshold for statistical significance. These values were extracted from Effect of resveratrol in combination with EPA in modulating the expression of pro-inflammation target genes in stimulated RAW macrophages of this article (see Table 1 and Supplementary Table S2 (available online at http://www. journals.cambridge.org/bjn) to find out which gene is up-, down- or nonregulated for each treatment). There were twelve anti-inflammatory (Tnfrsf1b, II-1rn, II-10, Nfkbia, Nfkbib, Pparg, Socs1, Socs2, Socs3, Hdac2, Sirt1, Timp1) and eight antioxidant (Hmox1, Cat, Gpx1, Nfe2l2, Gclm, Sod1, Sod2, Nqo1) genes detected in this study. 
Ptgs2 (Tables 1 and Table S2; available online at http://www. journals.cambridge.org/bjn). In this context, there is controversy with the ability of Res to modulate proinflammatory genes, with some studies reporting that Res cannot regulate them $^{(31,55)}$ and the others supporting our results ${ }^{(21,57)}$. In overview, our results suggest that Res helps to decrease inflammation by down-regulating proinflammatory target genes (Fig. 4), but that EPA decreases inflammation by up-regulating anti-inflammatory and antioxidant genes (Fig. 5). We found that the combination of Res and EPA promotes a greater down-regulation of proinflammatory target genes (Fig. 4) as well as a surprisingly remarkable down-regulation of anti-inflammatory and antioxidant-related genes (Fig. 5). Importantly (Table 1), combined treatment decreased proinflammatory $I l-1 \alpha$ and $\beta$, and $I l-6$ compared with the positive control. In addition, Tnf- $\alpha$, a molecule crucial in inflammation-related diseases and the activation of macrophages, was down-regulated, demonstrating a potentiated antiinflammatory effect when the molecules were combined. These results may be due to the ability of Res and EPA to decrease the levels of P-SAPK/JNK (Fig. 3(B)), which is able to lead the expression of IL- $1 \beta$ and TNF- $\alpha$, through the activation of AP-1. In contrast, the expression of antiinflammatory $\mathrm{Il}-10$ was decreased with the combination of compounds, which suggests that this combination could have inhibitory effects over the expression of antiinflammatory proteins or that the LPS-induced global inflammatory state was decreased by other pathways, rendering unnecessary its expression. On the other hand, proinflammatory chemokines, such as $C s f 2, C c l 2$ and $C c l 5$, were downregulated, reasserting the enhancer effect of the molecules in combination, which could suggest that the cells return to their normal levels of differentiation and production after $19 \mathrm{~h}$ of treatment under the influence of the molecules. Expression of Serpine1 (Pai-1), which encodes the inhibitor of plasminogen activator, was decreased, suggesting that this treatment could ameliorate the coagulation of blood around tissues with macrophages. In addition, expression levels of transcription factors and proteins related to inflammation pathways, such as $N F-\kappa B p 65$, the inhibitor of NF- $\mathrm{BB}$ kinase $I k k-\beta, M a p 3 k 8$, or $J n k 1$ were decreased, most of them as a consequence of the enhancer effect of the molecules in combination, in comparison with the positive control. In contrast, the expression of anti-inflammatory genes, such as histone deacetylase 2 (Hdac2), and suppressors of cytokine signalling 2 and 3 (Socs 2 and Socs3), were potentially downregulated, which suggests that cells return to the state of non-inflammation or non-activation and that they do not need the action of some anti-inflammatory mechanisms. In conclusion, the cells treated with Res and EPA had decreased global inflammation, affecting the gene expression of proteins related to NF- $\mathrm{KB}$ and $\mathrm{AP}-1$ pathways, and important proinflammatory interleukins, chemokines and cytokines. In oxidative stress-related genes, we found an increase in the expression of various antioxidant proteins, such as haemeoxygenase 1 (Hmox 1), which catalyses the degradation of haeme, catalase (Cat) and $\gamma$-glutamylcysteine synthetase regulatory subunit $(\mathrm{Gclm})$, which is the first rate-limiting enzyme of glutathione synthesis. These three proteins have been implicated in an reactive oxygen species-reduction pathway. However, these effects were not stronger than EPA up-regulation. In addition, iNos gene expression was downregulated when the molecules were combined, suggesting a reduction of the pro-oxidative stress effects promoted by LPS.

These results suggest that the combination of Res and EPA has an enhancer anti-inflammatory effect by modulating several inflammatory and oxidative stress-related genes. Furthermore, these inhibitory effects could result from the sum of the EPA-mediated up-regulation of antioxidant genes and Res-mediated down-regulation of proinflammatory genes.

\section{Conclusions}

Combining Res and EPA has potentiating anti-inflammatory effects in LPS-stimulated RAW 264.7 macrophages by decreasing NO levels, decreasing the mRNA levels of proinflammatory and oxidative stress-related genes and affecting the phosphorylation of proteins implicated in the activation of NF- $\mathrm{B}$ and AP-1 proinflammatory pathways. These results could lead to in vivo studies that may yield novel preventive or palliative nutritional treatments for obesity, atherosclerosis and CVD.

\section{Acknowledgements}

V. P. received a grant from the Rovira i Virgili University for PhD students, a grant from the Ministerio de Educación y Ciencia (MEYC) for students training to obtain the European Mention for a doctorate degree and grant AGL2008-00387 from the MEYC. A. C.-A. received an FPU fellowship from the Spanish Ministry of Science and Innovation (MICINN) and Lídia Cedó a predoctoral fellowship from the Generalitat de Catalunya. Moreover, this work was supported by grant AGL2008-01310 from the MEYC. V. P., D. C. and L. C. performed the experimental work. A. C.-A., M. P. and A. A. contributed to the discussion and revision of the manuscript. M. R., M. B. and L. A. contributed to the experimental design and supervision of the work. All authors contributed to the development, writing and review of this paper. We confirm that there are no conflicts of interest with any of the contributing authors in the content of the paper.

\section{References}

1. Ho S-C, Hwang LS, Shen Y-J, et al. (2007) Suppressive effect of a proanthocyanidin-rich extract from longan (Dimocarpus longan Lour.) flowers on nitric oxide production in LPS-stimulated macrophage cells. J Agric Food Chem 55, 10664-10670.

2. Maury E \& Brichard SM (2010) Adipokine dysregulation, adipose tissue inflammation and metabolic syndrome. Mol Cell Endocrinol 314, 1-16.

3. Holvoet P (2008) Relations between metabolic syndrome, oxidative stress and inflammation and cardiovascular disease. Verh K Acad Geneeskd Belg 70, 193-219.

4. Fujihara M, Muroi M, Tanamoto K, et al. (2003) Molecular mechanisms of macrophage activation and deactivation by 
lipopolysaccharide: roles of the receptor complex. Pharmacol Ther 100, 171-194.

5. Permana PA, Menge C \& Reaven PD (2006) Macrophagesecreted factors induce adipocyte inflammation and insulin resistance. Biochem Biophys Res Commun 341, 507-514.

6. Bowie A \& O'Neill LAJ (2000) Oxidative stress and nuclear factor-kappaB activation: a reassessment of the evidence in the light of recent discoveries. Biochem Pharmacol 59, $13-23$.

7. Aktan F (2004) iNOS-mediated nitric oxide production and its regulation. Life Sci 75, 639-653.

8. Ghosh S \& Karin M (2002) Missing pieces in the NF-kappaB puzzle. Cell 109, S81-S96.

9. Kunz M, Ibrahim S, Koczan D, et al. (2001) Activation of c-Jun $\mathrm{NH}_{2}$-terminal kinase/stress-activated protein kinase (JNK/SAPK) is critical for hypoxia-induced apoptosis of human malignant melanoma. Cell Growth Differ 12, $137-145$.

10. Hu X, Chen J, Wang L, et al. (2007) Crosstalk among Jak-STAT, toll-like receptor, and ITAM-dependent pathways in macrophage activation. J Leukoc Biol 82, 237-243.

11. Rahman I, Biswas SK \& Kirkham PA (2006) Regulation of inflammation and redox signaling by dietary polyphenols. Biochem Pharmacol 72, 1439-1452.

12. Arts ICW \& Hollman PCH (2005) Polyphenols and disease risk in epidemiologic studies. Am J Clin Nutr 81, 317S-325S.

13. Terra X, Montagut G, Bustos M, et al. (2009) Grape-seed procyanidins prevent low-grade inflammation by modulating cytokine expression in rats fed a high-fat diet. $J$ Nutr Biochem 20, 210-218.

14. Nichols JA \& Katiyar SK (2010) Skin photoprotection by natural polyphenols: anti-inflammatory, antioxidant and DNA repair mechanisms. Arch Dermatol Res 302, 71-83.

15. Surh Y-J (2006) NF-кB and AP-1 as molecular targets for chemoprevention with EGCG, a review. Environ Chem Lett 4, 137-141.

16. Na H-K \& Surh Y-J (2006) Intracellular signaling network as a prime chemopreventive target of (-)-epigallocatechin gallate. Mol Nutr Food Res 50, 152-159.

17. Terra X, Valls J, Vitrac X, et al. (2007) Grape-seed procyanidins act as antiinflammatory agents in endotoxin-stimulated RAW 264.7 macrophages by inhibiting NFkB signaling pathway. J Agric Food Chem 55, 4357-4365.

18. de la Lastra CA \& Villegas I (2005) Resveratrol as an antiinflammatory and anti-aging agent: mechanisms and clinical implications. Mol Nutr Food Res 49, 405-430.

19. Sánchez-Fidalgo S, Cárdeno A, Villegas I, et al. (2010) Dietary supplementation of resveratrol attenuates chronic colonic inflammation in mice. Eur J Pharmacol 633, 78-84.

20. de la Lastra CA \& Villegas I (2007) Resveratrol as an antioxidant and pro-oxidant agent: mechanisms and clinical implications. Biochem Soc Trans 35, 1156-1160.

21. Tsai S-H, Lin-Shiau S-Y \& Lin J-K (1999) Suppression of nitric oxide synthase and the down-regulation of the activation of $\mathrm{NF} \kappa \mathrm{B}$ in macrophages by resveratrol. Br J Pharmacol 126, 673-680.

22. Gogus U \& Smith C (2010) $n-3$ Omega fatty acids: a review of current knowledge. Int J Food Sci Technol 45, 417-436.

23. Rahman MM, Bhattacharya A \& Fernandes G (2008) Docosahexaenoic acid is more potent inhibitor of osteoclast differentiation in RAW 264.7 cells than eicosapentaenoic acid. J Cell Physiol 214, 201-209.

24. Calder PC (2005) Polyunsaturated fatty acids and inflammation. Biochem Soc Trans 33, 423-427.

25. Saw CLL, Huang Y \& Kong A-N (2010) Synergistic anti-inflammatory effects of low doses of curcumin in combination with polyunsaturated fatty acids: docosahexaenoic acid or eicosapentaenoic acid. Biochem Pharmacol 79, 421-430.

26. Calder PC (2006) n-3 Polyunsaturated fatty acids, inflammation, and inflammatory diseases. Am J Clin Nutr $\mathbf{8 3}$, 1505S-1519S.

27. Corning PA (1998) "The synergism hypothesis": on the concept of synergy and its role in the evolution of complex systems. J Soc Evol Syst 21, 133-172.

28. Chou T-C (2006) Theoretical basis, experimental design, and computerized simulation of synergism and antagonism in drug combination studies. Pharmacol Rev 58, 621-681.

29. Lee JJ, Kong M, Ayers GD, et al. (2007) Interaction index and different methods for determining drug interaction in combination therapy. J Biopharm Stat 17, 461-480.

30. Liang Y-C, Huang Y-T, Tsai S-H, et al. (1999) Suppression of inducible cyclooxygenase and inducible nitric oxide synthase by apigenin and related flavonoids in mouse macrophages. Carcinogenesis 20, 1945-1952.

31. Wadsworth TL \& Koop DR (1999) Effects of the wine polyphenolics quercetin and resveratrol on pro-inflammatory cytokine expression in RAW 264.7 macrophages. Biochem Pharmacol 57, 941-949.

32. Elbling L, Weiss R-M, Teufelhofer O, et al. (2005) Green tea extract and (-)-epigallocatechin-3-gallate, the major tea catechin, exert oxidant but lack antioxidant activities. FASEB J 19, 807-809.

33. Lee T-P, Leu S-JJ, Huang JC, et al. (2009) Anti-ribosomal phosphoprotein autoantibody triggers interleukin-10 overproduction via phosphatidylinositol 3-kinase-dependent signalling pathways in lipopolysaccharide-activated macrophages. Immunology 127, 91-102.

34. Ci X, Ren R, Xu K, et al. (2009) Schisantherin A exhibits antiinflammatory properties by down-regulating NF-kappaB and MAPK signaling pathways in lipopolysaccharide-treated RAW 264.7 cells. Inflammation 33, 126-136.

35. Lee HJ, Lim HJ, Lee DY, et al. (2010) Carabrol suppresses LPS-induced nitric oxide synthase expression by inactivation of p38 and JNK via inhibition of I-kappaBalpha degradation in RAW 264.7 cells. Biochem Biophys Res Commun 391, 1400-1404.

36. Jeong Sung Mi, Davaatseren M, Kim W, et al. (2009) Vitisin A suppresses LPS-induced NO production by inhibiting ERK, p38, and NF-kappaB activation in RAW 264.7 cells. Int Immunopharmacol 9, 319-323.

37. Hwang J-M, Yu J-Y, Jang Y-O, et al. (2010) A phenolic acid phenethyl urea compound inhibits lipopolysaccharideinduced production of nitric oxide and pro-inflammatory cytokines in cell culture. Int Immunopharmacol 10, $526-532$.

38. Scott MG, Rosenberger CM, Gold MR, et al. (2000) An alphahelical cationic antimicrobial peptide selectively modulates macrophage responses to lipopolysaccharide and directly alters macrophage gene expression. J Immunol $\mathbf{1 6 5}$, 3358-3365.

39. Dos Santos S, Delattre A-I, De Longueville F, et al. (2007) Gene expression profiling of LPS-stimulated murine macrophages and role of the NF-kappaB and PI3K/mTOR signaling pathways. Ann N Y Acad Sci 1096, 70-77.

40. Aung HT, Schroder K, Himes SR, et al. (2006) LPS regulates proinflammatory gene expression in macrophages by altering histone deacetylase expression. FASEB J 20, 1315-1327.

41. Mendes SDS, Candi A, Vansteenbrugge M, et al. (2009) Microarray analyses of the effects of NF-kappaB or PI3K pathway inhibitors on the LPS-induced gene expression profile in RAW 264.7 cells: synergistic effects of rapamycin 
on LPS-induced MMP9-overexpression. Cell Signal 21 1109-1122.

42. Vitaglione P, Sforza S, Galaverna G, et al. (2005) Bioavailability of trans-resveratrol from red wine in humans. Mol Nutr Food Res 49, 495-504.

43. Goldberg DM, Yan J \& Soleas GJ (2003) Absorption of three wine-related polyphenols in three different matrices by healthy subjects. Clin Biochem 36, 79-87.

44. Meng X, Maliakal P, Lu H, et al. (2004) Urinary and plasma levels of resveratrol and quercetin in humans, mice, and rats after ingestion of pure compounds and grape juice. J Agric Food Chem 52, 935-942.

45. Santos AC, Veiga F \& Ribeiro AJ (2011) New delivery systems to improve the bioavailability of resveratrol. Expert Opin Drug Deliv 8, 973-990.

46. la Porte C, Voduc N, Zhang G, et al. (2010) Steady-state pharmacokinetics and tolerability of trans-resveratrol $2000 \mathrm{mg}$ twice daily with food, quercetin and alcohol (ethanol) in healthy human subjects. Clin Pharmacokinet 49, 449-454.

47. Blasi E, Ardizzoni A, Colombari B, et al. (2007) NF-кB activation and p38 phosphorilation in microglial cells infected with Leptospira or exposed to partially purified leptospiral lipoproteins. Microb Pathog 42, 80-87.

48. Harasstani OA, Moin S, Tham CL, et al. (2010) Flavonoid combinations cause synergistic inhibition of proinflammatory mediator secretion from lipopolysaccharide-induced RAW 264.7 cells. Inflamm Res 59, 711-721.

49. Kim YJ \& Chung HY (2007) Antioxidative and antiinflammatory actions of docosahexaenoic acid and eicosapentaenoic acid in renal epithelial cells and macrophages. J Med Food 10, 225-231.

50. Komatsu W, Ishihara K, Murata M, et al. (2003) Docosahexaenoic acid suppresses nitric oxide production and inducible nitric oxide synthase expression in interferon-gamma plus lipopolysaccharide-stimulated murine macrophages by inhibiting the oxidative stress. Free Radic Biol Med 34, 1006-1016.

51. Lin YL \& Lin JK (1997) (-)-Epigallocatechin-3-gallate blocks the induction of nitric oxide synthase by down-regulating lipopolysaccharide-induced activity of transcription factor nuclear factor-kappaB. Mol Pharmacol 52, 465-472.

52. Chan MM, Mattiacci JA, Hwang HS, et al. (2000) Synergy between ethanol and grape polyphenols, quercetin, and resveratrol, in the inhibition of the inducible nitric oxide synthase pathway. Biochem Pharmacol 60, 1539-1548.

53. Huang Z, Wang C, Wei L, et al. (2008) Resveratrol inhibits EMMPRIN expression via P38 and ERK1/2 pathways in PMA-induced THP-1 cells. Biochem Biophys Res Commun 374, 517-521.

54. Lo CJ, Chiu KC, Fu M, et al. (2000) Fish oil modulates macrophage $\mathrm{P} 44 / \mathrm{P} 42$ mitogen-activated protein kinase activity induced by lipopolysaccharide. JPEN J Parenter Enteral Nutr 24, 159-163.

55. Djoko B, Chiou RY-Y, Shee J-J, et al. (2007) Characterization of immunological activities of peanut stilbenoids, arachidin-1, piceatannol, and resveratrol on lipopolysaccharide-induced inflammation of RAW 264.7 macrophages. J Agric Food Chem 55, 2376-2383.

56. Zhao Y, Joshi-Barve S, Barve S, et al. (2004) Eicosapentaenoic acid prevents LPS-induced TNF-alpha expression by preventing NF-kappaB activation. J Am Coll Nutr 23, 71-78

57. Chung EY, Kim BH, Hong J-T, et al. (2011) Resveratrol down-regulates interferon- $\boldsymbol{\gamma}$-inducible inflammatory genes in macrophages: molecular mechanism via decreased STAT-1 activation. J Nutr Biochem 22, 902-909. 